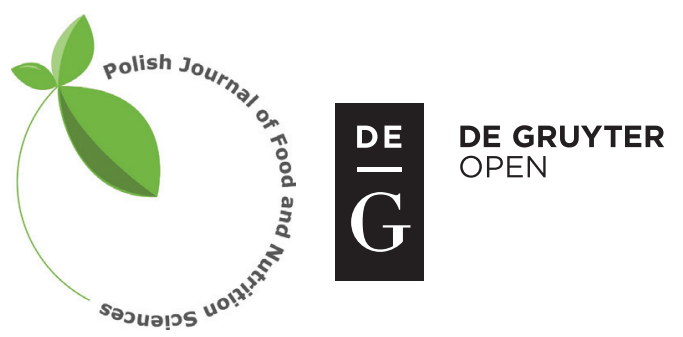

Pol. J. Food Nutr. Sci., 2016, Vol. 66, No. 4, pp. 271-276

DOI: $10.1515 /$ pjfns-2016-0007 http://journal.pan.olsztyn.pl

Original article

Section: Food Technology

\title{
Modelling the Colour of Strawberry Spread During Storage, Including Effects of Technical Variations
}

\author{
Mirta Kadivec', Leopold M.M. Tijskens², Mirela Kopjar ${ }^{3}$, Marjan Simčičč , Tomaž Požrl ${ }^{1 *}$ \\ ${ }^{l}$ Department of Food Science and Technology, Biotechnical Faculty, University of Ljubljana, \\ Ljubljana, Jamnikarjeva 101, 1000 Ljubljana, Slovenia \\ ${ }^{2}$ Horticulture and Product Physiology, Wageningen University and Research Centre, Wageningen, The Netherlands \\ ${ }^{3}$ Faculty of Food Technology, University of Osijek, Osijek, Croatia
}

Key words: strawberry spread, colour, modelling, technical variation

The colour of freshly processed strawberry spread changes relatively rapidly from a bright red to a dull red, which then makes its appearance generally less acceptable for consumers. The colours of strawberry spreads following several processing conditions were measured under different storage conditions. Additional sugar and colorant had only slight effects on the colour decay, while exclusion of oxygen and daylight did not affect this process. The only condition that clearly maintained the freshly processed appearance was storage at $4^{\circ} \mathrm{C}$. Hexagonal bottles were filled with the strawberry spreads and their colour was repeatedly measured at the six sides of the bottles, using a Minolta chroma meter. Data were analysed using non-linear indexed regression analysis based on a logistic function for the three colour aspect of $\mathrm{a}^{*}, \mathrm{~b}^{*}$ and $\mathrm{L}^{*}$. This technology allowed the determination of the variation in these data in terms of improved reliability $\left(\mathrm{R}_{\text {adj }}^{2},>90 \%\right)$. It also allowed better interpretation of the processes involved. All variations in the data could be attributed to technical variation.

\section{INTRODUCTION}

Visual perception of the colour of fresh and processed fruit is the first factor that affects quality perception, as this supersedes both flavour and textual perceptions [Ford et al., 1997]. The colouring compounds in strawberries are mostly anthocyanins, which are widely distributed water-soluble plant pigments [Mazza \& Miniati, 1993]. In strawberries, pelargonidin 3-glycoside is the predominant anthocyanin [Wang et al., 2002; Aaby et al., 2005] and it is largely responsible for the red colour of the fruit [Aaby et al., 2005].

The main factors that affect the final anthocyanin concentrations and the colour of a spread are the processing conditions [Garcia-Viguera \& Zafrilla, 2001], fruit variety, freezing period of the fruit prior to processing, and method of preparation [Gimenez et al., 2001; Talcott, 2007]. Additives to extend the shelf life of spreads can have an impact on their anthocyanin stability [Kopjar et al., 2008]. Ascorbic acid can accelerate anthocyanin degradation, and $\mathrm{pH}$ can have an impact on colour and pigment stability. Addition of pectin in viscous products increases the anthocyanin stability [Buchweitz et al., 2013], while the sugar concentration affects the colour stability due to a lower water activity [Hubbermann et al., 2006].

The temperature during storage of spreads has a major impact on colour and pigment stability. Spreads stored at

\footnotetext{
* Corresponding Author: Tel.: +386-1-3203716;

E-mail: tomaz.pozrl@bf.uni-lj.si (Tomaž Požrl)
}

$37^{\circ} \mathrm{C}$ show $98 \%$ pigment degradation after 3 months of storage, while those stored at $20^{\circ} \mathrm{C}$ show similar degradation after 6 months [Giusti \& Jing, 2007]. Furthermore, compared to low-temperature storage $\left(4^{\circ} \mathrm{C}\right)$ [Haffner et al., 2003], anthocyanin degradation is greater when spreads are stored at $20^{\circ} \mathrm{C}$ [Wicklund et al., 2005] or $15^{\circ} \mathrm{C}$ [Patras et al., 2011]. Fortunately, colour degradation is not as drastic as pigment degradation, which suggests that polymerised pigments and copigmentation reactions are important for the colour of these products during storage [Giusti \& Jing, 2007].

Through monitoring the effects of processing conditions and additives on the changes in colour of strawberry spreads, the main aim of this study was to determine the effects of the measuring techniques (i.e., of strawberry spread colour measurements using closed hexagonal jars) and the inevitable measuring errors induced by these techniques, through the application of novel approaches to data analysis.

\section{MATERIAL AND METHODS}

\section{Plant material}

Frozen strawberries (Fragaria $\times$ ananassa cv. 'Senga Sengana') were purchased from a local store in Kamnik (Slovenia) and stored at $-20^{\circ} \mathrm{C}$ until further use.

\section{Processing and storage conditions}

Frozen strawberries $(800 \mathrm{~g})$ were thawed in a microwave (Gorenje MMO 20) at $800 \mathrm{~W}$ for $2 \mathrm{~min}$. Thawed fruit mate- 
TABLE 1 . The strawberry spread components and storage conditions.

\begin{tabular}{|c|c|c|c|c|c|c|c|}
\hline \multirow{2}{*}{ Series } & \multicolumn{3}{|c|}{ Production } & \multicolumn{4}{|c|}{ Storage } \\
\hline & $\begin{array}{c}\text { Soluble } \\
\text { solids (\%) }\end{array}$ & Pectin $(\%)$ & $\begin{array}{c}\text { Natural } \\
\text { colorant }(\%)\end{array}$ & $\mathrm{N}_{2}$ & Temp $\left({ }^{\circ} \mathrm{C}\right)$ & Darkness & Daylight \\
\hline A & 38 & 0.6 & - & - & 20 & + & - \\
\hline B & 38 & 1.2 & - & - & 20 & + & - \\
\hline $\mathrm{C}$ & 43 & 0.6 & - & - & 20 & + & - \\
\hline $\mathrm{D}$ & 38 & 0.6 & - & - & 4 & + & - \\
\hline $\mathrm{E}$ & 38 & 0.6 & - & + & 20 & + & - \\
\hline $\mathrm{F}$ & 38 & 0.6 & 0.09 & - & 20 & + & - \\
\hline G & 38 & 0.6 & - & - & 20 & - & + \\
\hline
\end{tabular}

rial was blended in a mechanical blender (Stephan UMC 5 electronic; Hameln, Germany) for 90 s. Sugar (285 g), citric acid (3.5 g) and ascorbic acid (1.5 g) were added gradually. The pulp obtained was heated to $95^{\circ} \mathrm{C}$ under vacuum for $13 \mathrm{~min}$. The vacuum was removed, and the product was heated for additional $10 \mathrm{~min}$. In series F (see Table 1), a natural colorant $(1 \mathrm{~g})$ was added. Finally, the pectin mixture $(7 \mathrm{~g}$, or $14 \mathrm{~g}$ in series E; see Table 1) and sugar (15 g) were added slowly. The mixtures were then allowed to boil for another minute.

After cooling to $80^{\circ} \mathrm{C}$, hexagonal glass jars $(106 \mathrm{~mL}$ capacity) were filled with these spreads and pasteurised for $20 \mathrm{~min}$ at $80^{\circ} \mathrm{C}$. Total soluble solids were determined to ensure a Brix index of approximately 38, using a refractometer (Atago PAL-BX/RI; Tokyo, Japan). The spread was processed with seven different additives, all as six parallel series, and stored for 19 weeks under different storage conditions (see Table 1).

The ingredients used were obtained from the following sources: Pectin SF 560 from Danisco (USA), natural colorant Cherry red from Etol (Slovenia), citric acid from Anhui BBCA Biochemical Co., Ltd. (China), and ascorbic acid from Shandgong Luwei Pharmaceutical Co., Ltd (China).

\section{Colour measurements}

The colours of the spreads were measured using a Konica Minolta CR-400 chroma meter (Osaka, Japan), which was first calibrated against a standard white reflective plate. The colours were measured at the six hexagonal faces of three jars (as parallel measurements), at weekly intervals over 19 weeks. The data were recorded as the Commission Internationale de l'Éclairage colour coordinates of $\mathrm{a}^{*}, \mathrm{~b}^{*}$ and $\mathrm{L}^{*}$.

\section{Model development}

The major information on the colour changes of this red produce is contained in the a* value. Usually the colour changes occur in a sigmoid fashion, which has often been described with logistic functions [Tijskens et al., 2008, 2010; Unuk et al., 2012]. When expressed in the biological shift-factor notation, this logistic function is as shown in Equation (1):

$$
\mathrm{col}=\frac{\mathrm{col}_{\max }-\mathrm{col}_{\min }}{1+\mathrm{e}^{-\left(\mathrm{col}_{\max }-\mathrm{col}_{\min }\right) \cdot \mathrm{k}_{\mathrm{c}} \cdot(\mathrm{t}+\Delta \mathrm{t})}}+\mathrm{col}_{\min }
$$

where col is the measured colour (i.e., the $\mathrm{a}^{*}, \mathrm{~b}^{*}$ or $\mathrm{L}^{*}$ value), $\mathrm{Col}_{\max }$ is the maximum and $\mathrm{Col}_{\min }$ is the minimum colour that the samples can possibly reach at + or - infinite time, $\Delta \mathrm{t}$ is the shift factor (in days), $\mathrm{t}$ is the time (in days), and $\mathrm{k}_{\mathrm{c}}$ is the reaction rate constant (in $\mathrm{L} / \mathrm{mol} /$ day). Here, $\Delta \mathrm{t}$ is a stochastic parameter that is different for each individual sample, and it expresses the colour development in terms of the time of the colour change relative to the midpoint of the sigmoid curve. Preliminary analyses showed that the ranges of the changes in the colour values (i.e., $\mathrm{col}_{\max }-\mathrm{Col}_{\min }$ ) were approximately constant per combination of processing condition and jar side. The reordering of Equation (1) provides Equation (2), which is the final equation that was used in the analyses of all of the colour values.

$$
c o l=\frac{c o l_{r}}{1+\mathrm{e}^{-c o l_{r} \cdot k_{c} \cdot(t+\Delta t)}}+c o l_{\min }
$$

where col is the measured colour (i.e., the $\mathrm{a}^{*}, \mathrm{~b}^{*}$ or $\mathrm{L}^{*}$ value), and $\mathrm{col}_{\mathrm{r}}$ is the range of the change.

\section{Statistical analysis}

The model development and the mathematical deductions were conducted in Maple 14 (MapleSoft, Waterloo Maple Inc, Waterloo, Canada), which is a computer programme that is used to handle and solve algebraic and differential equations.

The data were analysed using the indexed non-linear regression procedure 'nls' of package R (R Development Core Team $R, 2005$ ), based on Equation (2). The concept of 'indexed' indicates that some parameters $\left(\mathrm{k}_{\mathrm{c}}, \Delta \mathrm{t}, \mathrm{col}_{\mathrm{r}}\right)$ were estimated in common for all of the individual samples (i.e., fixed effects), while the minimum asymptote $\mathrm{col}_{\text {min }}$ was estimated as a stochastic parameter for each side of each jar (i.e., random effects), to determine the variation in the samples. The normality of the distributions was tested using Shapiro-Wilk tests in package R.

\section{RESULTS}

\section{Raw data}

The range over which the colour aspects changed during storage was the largest for $\mathrm{a}^{*}$, while $\mathrm{b}^{*}$ and $\mathrm{L}^{*}$ showed consid- 
erably smaller ranges than expected for a red-coloured product. The variation over the different processing conditions and jar sides, however, was smallest for $\mathrm{a}^{*}$ relative to the range of changes. Indeed, for the colour aspects $b^{*}$ and $L^{*}$, the variation was larger than the ranges of the changes. Figure 1 shows some examples for all three of the colour aspects under the same processing conditions. For the other processing conditions, the results were similar. The range of the changes and the existing variation can be seen in the cloud of points around the mean behaviour (i.e., the simulated line).

\section{Analysis per production series}

Apparently, the magnitudes of the variation did not change with time. This would signify that there was a shift in the lower limits for the different series of production procedures and jar sides. Biological variation of the plant material was not very likely after the intense blending and mixing applied during the processing. This implies that the variation was caused by technical variation between the different jars and the jar sides, since no other type of variation exists. Purely technical variation induced by aberrations in the thick- ness and structure of the jar sides makes it also plausible that the ranges of the changes were relatively constant per processing condition. The data were therefore analysed per processing condition using indexed non-linear regression based on Equation (2), with variation of the lower asymptote $\left(\mathrm{col}_{\min }\right)$ per jar side, while at the same time estimating the other parameters $\left(\mathrm{col}_{\mathrm{r}}, \mathrm{k}_{\mathrm{c}}, \Delta \mathrm{t}\right)$ in common for all of the combinations. These data are shown in Table 2.

The explained parts $\left(\mathrm{R}_{\text {adj }}^{2}\right)$ were all high $(>90 \%)$, except for series D (see Table 2). The full ranges of the colour changes were not reached in this series, due to storage at a much lower temperature $\left(4^{\circ} \mathrm{C}\right)$. The standard errors of the estimates obtained were all low $(\leq 10 \%)$. For each colour aspect, the ranges of the changes $\left(\mathrm{col}_{\mathrm{r}}\right)$ and the shift factor $(\Delta \mathrm{t})$ were similar under all of the experimental conditions, except again for the series with storage at $4^{\circ} \mathrm{C}$. This probably signifies that the existing variation in asymptote values is indeed technical one, which was caused by the constant differences in the aberrations in the different jar surfaces. In other words, the variations were technical variations induced by the structure and thickness of the sides of the glass jars.
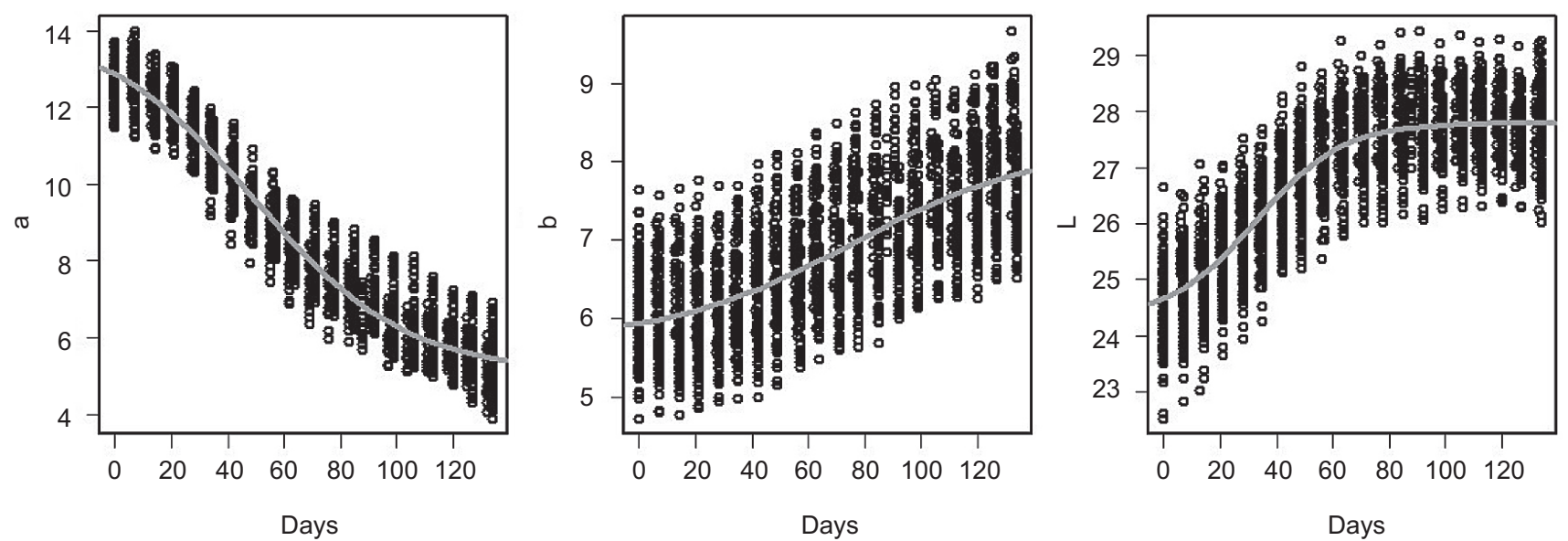

FIGURE 1. Raw data of the colour aspect for processing condition A, showing the range of the changes and the existing variation. The lines represent the simulated mean behaviour based on the estimated parameter values, as shown in Table 2.
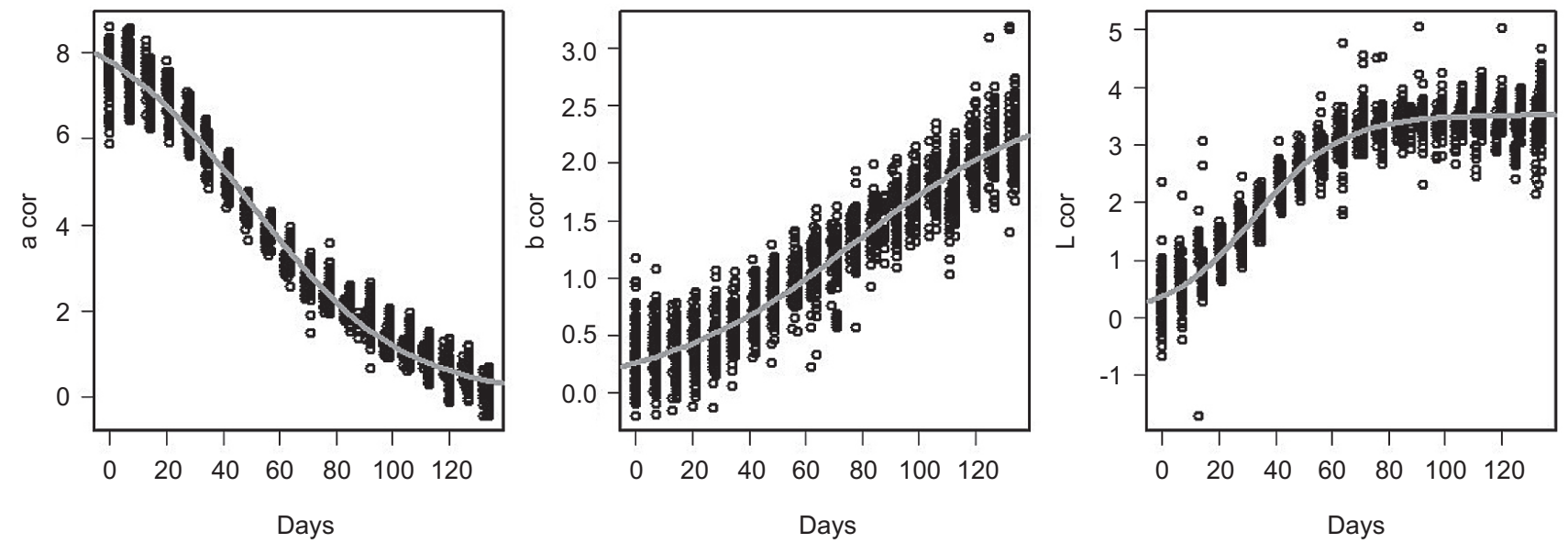

FIGURE 2. Corrected data of the colour aspects ( $\mathrm{col}_{-\mathrm{col}}{ }_{\min }$ ) for processing condition A. Some of the variation remains unexplained (i.e., the width of the cloud of points around the simulated lines). The lines represent the simulated mean behaviours based on the estimated parameter values, as shown in Table 2. 
TABLE 2. Result of the combined analysis of the three colour aspects for each processing procedure.

\begin{tabular}{|c|c|c|c|c|c|c|c|c|c|c|c|c|c|c|}
\hline \multirow{2}{*}{$\mathrm{Col}$} & \multirow{2}{*}{ Series } & \multicolumn{4}{|c|}{ Parameter } & \multicolumn{4}{|c|}{ Standard error of estimate } & \multicolumn{3}{|c|}{ Admin } & \multicolumn{2}{|c|}{ Stochastic } \\
\hline & & $\mathrm{col}_{\mathrm{r}}$ & $\Delta \mathrm{t}$ & $\mathrm{k}_{\mathrm{c}}$ & $\mathrm{col}_{\text {min }}$ & $\mathrm{col}_{\mathrm{r}}$ & $\Delta \mathrm{t}$ & $\mathrm{k}_{\mathrm{c}}$ & $\mathrm{Col}_{\text {min }}$ & $\mathrm{R}_{\text {adj }}^{2}$ & $\mathrm{~N}_{\mathrm{obs}}$ & $\mathrm{N}_{\text {group }}$ & $\mathrm{sd} \cdot \mathrm{col}_{\min }$ & p.col ${ }_{\text {min }}$ \\
\hline a & A & 9.01 & -49.63 & -0.0041 & 5.09 & 0.13 & 0.55 & 0.0001 & 0.12 & 0.98 & 2157 & 108 & 0.50 & 0.53 \\
\hline $\mathrm{a}$ & $\mathrm{B}$ & 8.54 & -51.23 & -0.0041 & 5.25 & 0.13 & 0.59 & 0.0002 & 0.12 & 0.98 & 2138 & 107 & 0.77 & 0.20 \\
\hline $\mathrm{a}$ & $\mathrm{C}$ & 7.17 & -64.30 & -0.0043 & 4.44 & 0.13 & 0.57 & 0.0002 & 0.10 & 0.98 & 2160 & 108 & 0.50 & 0.04 \\
\hline $\mathrm{a}$ & $\mathrm{D}$ & 11.20 & -156.55 & -0.0055 & 1.75 & - & 1.19 & 0.0002 & 0.12 & 0.81 & 2145 & 108 & 0.93 & 0.00 \\
\hline $\mathrm{a}$ & $\mathrm{E}$ & 9.31 & -50.90 & -0.0036 & 5.07 & 0.15 & 0.63 & 0.0001 & 0.14 & 0.98 & 2154 & 108 & 0.61 & 0.26 \\
\hline $\mathrm{a}$ & $\mathrm{F}$ & 8.16 & -54.51 & -0.0034 & 5.47 & 0.22 & 0.93 & 0.0002 & 0.16 & 0.97 & 2156 & 108 & 0.53 & 0.63 \\
\hline $\mathrm{a}$ & $\mathrm{G}$ & 9.57 & -36.16 & -0.0036 & 5.32 & 0.20 & 1.00 & 0.0002 & 0.19 & 0.98 & 2150 & 108 & 0.53 & 0.01 \\
\hline $\mathrm{b}$ & A & 2.64 & -77.81 & 0.0108 & 5.67 & 0.12 & 1.59 & 0.0012 & 0.07 & 0.95 & 2157 & 108 & 0.63 & 0.04 \\
\hline b & B & 2.72 & -73.97 & 0.0107 & 5.41 & 0.12 & 1.35 & 0.0011 & 0.07 & 0.94 & 2138 & 107 & 0.56 & 0.40 \\
\hline b & $\mathrm{C}$ & 1.80 & -91.04 & 0.0225 & 4.71 & 0.07 & 1.65 & 0.0021 & 0.05 & 0.91 & 2160 & 108 & 0.47 & 0.14 \\
\hline b & $\mathrm{D}$ & 2.24 & -135.87 & 0.0099 & 5.90 & - & 2.89 & 0.0008 & 0.10 & 0.72 & 2145 & 108 & 0.60 & 0.58 \\
\hline b & $\mathrm{E}$ & 2.19 & -73.08 & 0.0157 & 5.72 & 0.09 & 1.32 & 0.0016 & 0.07 & 0.91 & 2154 & 108 & 0.53 & 0.49 \\
\hline b & $\mathrm{F}$ & 1.35 & -81.06 & 0.0300 & 5.01 & 0.07 & 1.86 & 0.0039 & 0.06 & 0.87 & 2156 & 108 & 0.51 & 0.00 \\
\hline b & G & 1.67 & -49.80 & 0.0335 & 5.81 & 0.04 & 0.86 & 0.0022 & 0.06 & 0.91 & 2150 & 108 & 0.53 & 0.09 \\
\hline $\mathrm{L}$ & A & 3.52 & -32.79 & 0.0185 & 24.28 & 0.06 & 0.66 & 0.0009 & 0.09 & 0.94 & 2157 & 108 & 0.60 & 0.75 \\
\hline $\mathrm{L}$ & B & 3.60 & -31.34 & 0.0162 & 24.09 & 0.07 & 0.79 & 0.0008 & 0.09 & 0.95 & 2138 & 107 & 0.63 & 0.20 \\
\hline $\mathrm{L}$ & $\mathrm{C}$ & 2.89 & -38.59 & 0.0177 & 23.24 & 0.07 & 1.00 & 0.0011 & 0.09 & 0.93 & 2160 & 108 & 0.59 & 0.53 \\
\hline $\mathrm{L}$ & D & 3.94 & -149.00 & 0.0197 & 24.38 & - & 2.28 & 0.0022 & 0.13 & 0.57 & 2145 & 108 & 0.63 & 0.00 \\
\hline $\mathrm{L}$ & E & 3.59 & -30.96 & 0.0164 & 24.02 & 0.08 & 0.82 & 0.0009 & 0.10 & 0.94 & 2154 & 108 & 0.62 & 0.48 \\
\hline $\mathrm{L}$ & $\mathrm{F}$ & 3.15 & -28.02 & 0.0175 & 23.33 & 0.11 & 1.37 & 0.0014 & 0.13 & 0.92 & 2156 & 108 & 0.72 & 0.07 \\
\hline $\mathrm{L}$ & G & 3.69 & -25.79 & 0.0199 & 24.13 & 0.07 & 0.63 & 0.0009 & 0.09 & 0.95 & 2150 & 108 & 0.63 & 0.98 \\
\hline
\end{tabular}

The standard deviation of the lower asymptote ( $\mathrm{sd}^{\mathrm{c} . \mathrm{col}_{\text {min }}}{ }_{\text {) }}$ was about the same for all of the processing conditions. This is also an indication that the variation was technical variation. The majority of the distributions of $\mathrm{col}_{\text {min }}$ can be considered normal, as indicated by the probability of the Shapiro-Wilk tests (p.col ${ }_{\text {min }}$ ) being above 0.05 .

The individually measured colour data were corrected for the lower asymptote $\left(\mathrm{col}_{-} \mathrm{col}_{\min }\right)$ as estimated for this series, which effectively removed the variation in the data. Figure 2 shows these corrected data for the same processing conditions as used in Figure 1. There is still some variation left that is not taken into account by the model and the analysis. It is however likely that also this unexplained variation is a technical variation, which might have been induced by different light conditions (i.e., stray light) during the measurements.

\section{Effects of the processing and storage conditions}

To determine the effects of the different processing conditions, the simulated behaviour for the mean value of the lower asymptote is shown in Figure 3. For the $a^{*}$ value, there were almost no effects of the processing conditions, except for the slightly darker initial colour at the high soluble solids content (series C). Only the lower storage temperature (series D) clearly had beneficial effects. For $\mathrm{b}^{*}$ and $\mathrm{L}^{*}$, the additional soluble solids (series C) and the additional colorant (series F) appeared to cause darker initial colour, as can be seen from the lower asymptote, as well as darker final colour (upper asymptote), although these conditions did not affect the mechanism at work. In view of the small range of the change for these aspects, the effects on perception by the human eye will be negligible. The effects of storage temperature on the behaviour of $\mathrm{L}^{*}$ showed the same effects as for $\mathrm{a}^{*}$, while the effects on $b^{*}$ appeared to be less pronounced. Apparently the yellowing is less sensitive to temperature.

\section{DISCUSSION}

The lower storage temperature had a beneficial effect on colour retention and anthocyanins content in strawberry jams [Mazur et al., 2014]. Storing the products at $4^{\circ} \mathrm{C}$ in the dark was indispensable for colour and pigment retention, while illumination resulted in rapid discolouration [Holzwarth et al., 2013]. The colour of anthocyanins is preserved much better when kept in the dark [Cavalcanti et al., 2011]. The presence of oxygen can amplify the anthocyanins degradation through different mechanisms [Patras et al., 2010]. However, gas con- 

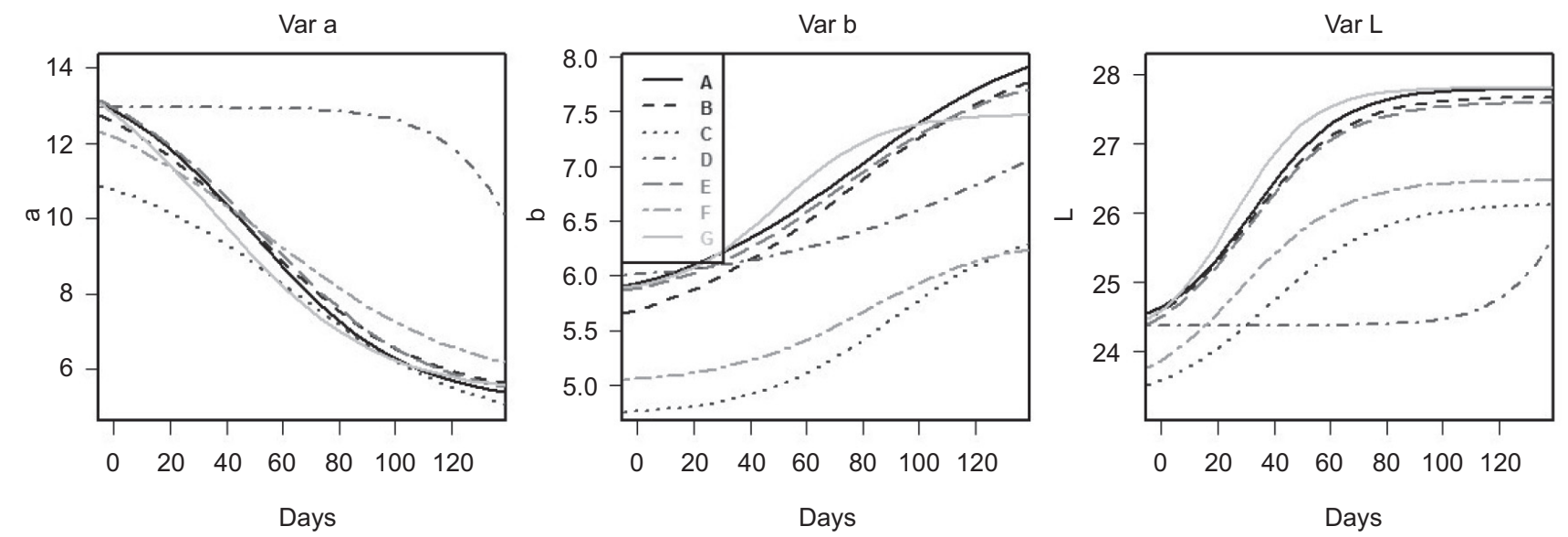

FIGURE 3. Simulated behaviours of all three of the colour aspects for the six processing conditions based on the estimated parameter values, as shown in Table 2.

ditions (air vs. nitrogen) had no effect on anthocyanin loss during storage of strawberry juice [Bakker et al., 1992]. Exclusion of daylight during the storage, or of oxygen at the time of jar filling, did not affect the change in colour, neither kinetics nor level. The addition of pectin markedly enhanced anthocyanin stability [Buchweitz et al., 2013]. In our study, however, the addition of pectin did not have any protective effect on colour stability of the strawberry spreads.

Sugar at concentrations higher than $20 \%$, did not to prevent significantly the decay of anthocyanins and colour in berries [Nikkhah et al., 2007]. On the other hand, a positive effect of sugar on colour retention was reported [Hubbermann et al., 2006], presumably due to lower water activity. Colour stability of strawberry syrup was greatly improved by increasing the concentration of anthocyanins [Cavalcanti et al., 2011]. We found that higher sugar content or higher anthocyanins concentration had only slight effects on colour deterioration rate during storage.

In short, except low temperature storage, all methods tested to achieve the greater colour stability (i.e., storing in the darkness, use of nitrogen for oxygen elimination, addition of pectin, addition of sugar, addition of colorant) were ineffective.

\section{CONCLUSIONS}

The range of the changes in colour of stored strawberry spread was, as expected, the largest for $a^{*}$, while for $b^{*}$ and $\mathrm{L}^{*}$ they were relatively small. Thus, the visual perception of colour will be determined for the most part by the $\mathrm{a}^{*}$ value. The processing conditions had only minor effects on colour changes. Daylight and exclusion of oxygen also had little effect on the changes in colour for all three of these colour aspects. The addition of soluble solids and colorant had slight darkening effects. Temperature during storage was the only factor that affected the kinetics of colour changes (rate of change). The remaining processing conditions only affected the value of the model parameters $\operatorname{col}_{\mathrm{r}}$ and $\mathrm{col}_{\text {min }}$ (range of change).

Colour changes of strawberry spreads during storage can be described by logistic functions in terms of all three of the colour aspects, $\mathrm{a}^{*}, \mathrm{~b}^{*}$ and $\mathrm{L}^{*}$. Indexed non-linear regression analysis on the data from the same samples in time was very powerful for the determination of the variation, and this considerably increased the reliability of the analysis. By including the variations in the analysis, the effects of the experimental conditions can be interpreted more clearly.

The system for measuring the colour of a semisolid produce such as marmalade, spread, jelly, dough during longer period (including the possibility of pasteurisation) in hexagonal or square jars seems quite applicable, especially when some modifications will be applied (e.g., shielding of direct and stray light), since the majority of variation in the data can be traced back to the glass structure by using the indexed non-linear regression technology.

The problem of discolouration of strawberry spreads can only be solved by investigating the real reasons and mechanisms behind the changes in anthocyanin degradation (i.e., the changes in reddishness) and polyphenols (i.e., browning). This analysis technology offers advantages for the unravelling of the mechanisms at work here. Further research on this topic will be undertaken.

\section{RESEARCH FUNDING}

This study was financed by statutory funds of the Department of Food Science and Technology, Biotechnical Faculty, University of Ljubljana.

\section{CONFLICT OF INTEREST}

None declared.

\section{REFERENCES}

1. Aaby K., Skrede G., Worlstad R.E., Polyphenolic composition and antioxidant activities in flesh and achenes of strawberries (Fragaria ananasa). J. Agric. Food Chem., 2005, 53, 4032-4040.

2. Buchweitz M., Speth M., Kammerer D.R., Carle R., Impact of pectin type on the storage stability of blackcurrant (Ribes nigrum L.) anthocyanins in pectic model solutions. Food Chem., 2013, 139, 1168-1178. 
3. Bakker J., Bridle P., Koopman A., Strawberry juice colour: the effect of some processing variables on the stability of anthocyanins. J. Sci. Food Agric., 1992, 60, 471-476.

4. Cavalcanti R.N., Santos D.T., Meireles M.A.A., Non-thermal stabilization mechanisms of anthocyanins in model and food systems - an overview. Food Res. Int., 2011, 44, 499-509.

5. Ford A., Hansen K., Herrington M., Moisander J., Notthingham S., Prytz S., Zorin M., Subjective and objective determination of strawberry quality. Acta Hortic., 1997, 439, 319-324.

6. Garcia-Viguera C., Zafrilla P., Changes in anthocyanin during food processing: influence on color. 2001, in: Chemistry and Physiology of Selected Food Colourants (eds. J.M. Ames, T. Hofmann). Oxford University Press, New York, pp. 56-65.

7. Gimenez J., Kajda P., Margemenon L., Piggott J.R., Zabetakis I., A study on the colour and sensory attributes of high-hydrostaticpressure jams as compared with traditional jams. J. Sci. Food Agric., 2001, 81, 1228-1234.

8. Giusti M.M., Jing P., Natural pigments of berries: Functionality and application. 2007, in: Berry Fruit: Value-Added Products for Health Promotion (ed. Y. Zhao). CRC Press, Boca Raton, pp. 105-146.

9. Haffner K., Finstad M.B., Rosenfeld H.J., Skrede G., Colour of raspberry jam as influenced by cultivar, temperature and light during storage. Acta Hortic., 2003, 628, 829-834.

10. Holzwarth M., Korhummel S., Siekmann T., Carle R., Kammerer D.R., Influence of different pectins, process and storage conditions on anthocyanin and colour retention in strawberry jams and spreads. LWT - Food Sci. Technol., 2013,52, SI, 131-138.

11. Hubbermann E.M., Heins A., Stockmann H., Schwarz K., Influence of acids, salt, sugars and hydrocolloids on the colour stability of anthocyanin-rich blackcurrant and elderberry concentrates. Eur. Food Res. Technol., 2006, 223, 83-90.

12. Kopjar M., Piližota V., Hribar J., Simčič M., Zlatič E., Nedić Tiban N., Influences of trehalose addition and storage conditions on the quality of strawberry cream filling. J. Food Eng., 2008, 87, 341-350.

13. Mazur S.P., Nes A., Wold A-B., Remberg S.F., Martinsen B.K., Aaby K., Effects of ripeness and cultivar on chemical composition of strawberry (Fragaria $\mathrm{x}$ ananassa Duch.) fruits and their suitability for jam production as a stable product at different storage temperatures. Food Chem., 2014, 146, 412-422.
14. Mazza G., Miniati E., Anthocyanins in fruits, vegetables and grains. 1993, CRC Press, Boca Raton, USA, p. 362.

15. Nikkhah E., Khayamy M., Heidari R., Jamee, R., Effect of sugar treatment on stability of anthocyanin pigments in berries. J. Biol. Sci., 2007, 7, 1412-1417.

16. Patras A., Brunton N.P., O'Donnell C., Tiwari B.K., Effect of thermal processing on anthocyanin stability in foods; mechanisms and kinetics of degradation. Trends Food Sci. Technol., 2010, 21, 3-11.

17. Patras A., Brunton N.P., Tiwari B.K., Butler, F., Stability and degradation kinetics of bioactive compounds and colour in strawberry jam during storage. Food Bioprocess Technol., 2011, 4, $1245-1252$.

18. R Development Core Team R. 2005. A language and environment for statistical computing', R Foundation for Statistical Computing, Vienna, Austria. See [http://www.R-project.org].

19. Talcott S.T., Chemical components of berry fruits. 2007, in: Berry Fruit: Value-Added Products for Health Promotion (ed. Y. Zhao). CRC Press, Boca Raton, pp. 51-72.

20. Tijskens L.M.M., Konopacki P.J., Schouten R.E., Hribar J., Simčič M., Biological variance in the colour of Granny Smith apples: modelling the effect of senescence and chilling injury. Postharv. Biol. Technol., 2008, 50, 153-163.

21. Tijskens L.M.M., Schouten R.E., Konopacki P.J., Hribar J., Simčič, M., Modelling the biological variance of the yellow aspect of Granny Smith apple colour. J. Sci. Food Agric., 2010, 90, 798-805.

22. Unuk T., Tijskens L.M.M., Germšek B., Zadravec P., Vogrin A., Hribar J., Simčič M., Tojnko S., Effect of location in the canopy on the colour development of three apple cultivars during growth. J. Sci. Food Agric., 2012, 92, 2450-2458.

23. Wang S.Y., Zheng W., Galletta G.J., Cultural system affect fruit quality and antioxidant capacity in strawberries. J. Agric. Food Chem., 2002, 50, 6534-6542.

24. Wicklund T., Rosenfeld H.J., Martinsen B.K., Sundfør M.W., Lea P., Bruun T., Blomhoff R., Haffner K., Antioxidant capacity and colour of strawberry jam as influenced by cultivar and storage conditions. LWT - Food Sci. Technol., 2005, 38, 387-391.

Submitted: 2 July 2015. Revised: 29 January and 19 February 2016. Accepted: 12 April 2016. Published on-line: 30 August 2016. 